\title{
Estimating the Residency Expansion Required to Avoid Projected Primary Care Physician Shortages by 2035
}

\author{
Stephen M. Petterson, $\mathrm{PbD}^{1}$ \\ Winston R. Liaw, MD, MPH ${ }^{2}$ \\ Carol Tran, $M D^{3}$ \\ Andrew W. Bazemore, MD, MPH \\ 'Robert Graham Center, Washington, DC \\ ${ }^{2}$ Virginia Commonwealth University, Rich- \\ mond, Virginia
}

${ }^{3}$ University of Virginia, Charlottesville, Virginia
Conflicts of interest: authors report none.

\section{CORRESPONDING AUTHOR}

Winston R. Liaw, MD, MPH

3650 Joseph Siewick Dr, \#400

Fairfax, VA 22033

winstonrliaw@gmail.com

\begin{abstract}
PURPOSE The purpose of this study was to calculate the projected primary care physician shortage, determine the amount and composition of residency growth needed, and estimate the impact of retirement age and panel size changes.

METHODS We used the 2010 National Ambulatory Medical Care Survey to calculate utilization of ambulatory primary care services and the US Census Bureau to project demographic changes. To determine the baseline number of primary care physicians and the number retiring at 66 years, we used the 2014 American Medical Association Masterfile. Using specialty board and American Osteopathic Association figures, we estimated the annual production of primary care residents. To calculate shortages, we subtracted the accumulated primary care physician production from the accumulated number of primary care physicians needed for each year from 2015 to 2035.
\end{abstract}

RESULTS More than 44,000 primary care physicians will be needed by 2035 . Current primary care production rates will be unable to meet demand, resulting in a shortage in excess of 33,000 primary care physicians. Given current production, an additional 1,700 primary care residency slots will be necessary by 2035 . A $10 \%$ reduction in the ratio of population per primary care physician would require more than 3,000 additional slots by 2035 , whereas changing the expected retirement age from 66 years to 64 years would require more than 2,400 additional slots.

CONCLUSIONS To eliminate projected shortages in 2035, primary care residency production must increase by $21 \%$ compared with current production. Delivery models that shift toward smaller ratios of population to primary care physicians may substantially increase the shortage.

Ann Fam Med 2015;13:107-114. doi: 10.1370/afm.1760.

\section{INTRODUCTION}

The demands of an expanding, aging, and increasingly insured population have created concern about the sufficiency of our health care workforce. Already there are rising costs, unnecessary treatment, and undesirable levels of emergency department visits. ${ }^{1-3}$ Provisions in the Patient Protection and Affordable Care Act (ACA) support primary care physicians with the aspiration that a reinvigorated primary care workforce can "bend the cost curve." Initiatives, such as Family Medicine for America's Health, aim to develop the next generation of primary care physicians but lack guidance regarding how training will need to change. ${ }^{5}$

Using similar methods and data sources, numerous studies have sought to project the future need and supply for primary care. In 2008, Colwill et al projected a shortage of 44,000 primary care physicians by $2025 .^{6}$ The Association of American Medical Colleges (AAMC) came to a similar conclusion, projecting a shortage of 46,000 primary care physicians by 2025.7 In 2013, the Health Resources and Services Administration (HRSA) projected a shortage of 20,400 primary care physicians by $2020 .{ }^{8}$ Our own estimates projected a need for 52,000 primary care physicians by 2025 but did not include an estimate of future supply. ${ }^{9}$ 
Prior supply projections have assumed production will remain constant and estimated new primary care physicians based on overall physician supply growth. For instance, HRSA estimated that by 2020, the number of primary care physicians would increase $8 \%$ by assuming that $31.9 \%$ of new physicians will be primary care physicians. ${ }^{10,11}$ There is no reason to believe that production of primary care physicians will remain static, however. According to Chen et al, only $25.2 \%$ of all residents graduating between 2006 and 2008 practiced primary care in $2011 .^{12}$ The same study estimated $40 \%$ of internal medicine residents do not subspecialize, a finding similar to figures from the AAMC." Simultaneously, a growing number of general internal medicine physicians are leaving primary care to become hospitalists. ${ }^{13}$

To improve health care delivery, primary care physicians have experimented with new models, each of which affects panel sizes. For example, to implement patient-centered medical homes, the Group Health Cooperative of Puget Sound reduced panel sizes from 2,327 to $1,800 .{ }^{14}$ Others have argued that shifting work to nonphysicians (including nurse practitioners, physician assistants, and medical assistants) allows for larger panels. ${ }^{15}$ At the same time, this growing number of clinicians have gravitated to direct primary care (an emerging delivery model), which has been associated with dramatic panel contractions. ${ }^{16,17}$ The impetus for change lies in improving quality and reducing burnout. ${ }^{18}$ If successful, these models may influence not only panel sizes but also retirement ages. Although studies estimate that physicians retire around age 66 years, ${ }^{7}$ efforts to reduce administrative burdens could encourage primary care physicians to practice longer.

In light of uncertainty regarding future trends, this study addresses 3 questions: (1) What is the projected primary care physician shortage through 2035, accounting for retirement and assuming current levels of residency production? (2) How many additional residency slots by primary care specialty are needed to address this shortage? (3) How do changes in the retirement age and panel size (as determined by the ratio of population to primary care physician) affect the shortage?

\section{METHODS}

\section{Baseline Number of Primary Care Physicians}

To establish a 2015 baseline, by using the American Medical Association (AMA) Masterfile, we estimated the number of primary care physicians from 2010 to 2014 based on the same methods developed in previous work. ${ }^{9}$ Specifically, we restricted our counts of physicians in direct patient care to those with a primary, self-designated specialty of family medicine, general practice, general internal medicine, and general pediatrics. General practice refers to physicians without residency training; because nearly all physicians in the last few decades had such training, general practitioners still in the workforce are relatively few and near retirement age. We classified geriatricians as either general internists or family physicians based on their residency training. We classified physicians with medicinepediatrics training as pediatricians. These counts were adjusted for the AMA's undercount of retirees and for physicians with a primary care specialty working as hospitalists or in non-primary care settings. To obtain 2015 figures, we used a linear interpolation for each of the 4 specialties based on 2010 to 2014 projections.

\section{Demand for Physicians by Specialty}

We estimated current US primary care utilization rates by patient's age and physician specialty using the 2010 National Ambulatory Medical Care Survey (NAMCS), rather than the Medical Expenditure Panel Survey (MEPS), which was used in our previous work. ${ }^{9}$ NAMCS is based on sampling physicians from the AMA Masterfile, ensuring accurate counts by specialty. In contrast, specialty in the MEPS is patient-reported, and respondents have difficulty differentiating among different types of primary care physicians, overstating the number of general practitioners.

Using the NAMCS data, we calculated mean office visits to family physicians, general internists, and pediatricians for 7 age-groups: 0-4, 5-14, 15-17, $18-25,26-44,45-64$, and 65 years and older. We also used population projections from the 2010 US Census, which estimated lower rates of growth (total population estimate of 370 million) than the 2000 US Census (total population estimate of 390 million). ${ }^{19}$

To project primary care physicians needed by specialty, we multiplied age- and specialty-specific visit rates by projected populations to calculate total visits for each group. These projected visits were adjusted in 2 ways. First, because NAMCS focuses on office visits, to reconcile the NAMCS and AMA Masterfile primary care physician counts, we multiplied visits by the ratio of primary care physicians in the AMA Masterfile and the NAMCS. Second, given the greater use of services by the newly insured population under the ACA, we increased the number of visits by 6.8 million, phased in over a 20-year period. This figure is the product of the mean number of visits and 7,000 primary care physicians, the lower end of estimated additional primary care physicians needed resulting from the ACA. ${ }^{20,21}$ After these adjustments, assuming that visits per primary care physician are constant at 2015 levels, we calculated the number of primary care physicians required by dividing projected visits to each specialty by mean 
visits in 2015 per primary care physician. We also calculated the number of primary care physicians required resulting solely from population growth by multiplying the projected population from 2015 to 2035 by the 2015 ratio of primary care physicians to population.

\section{Current Supply of Primary Care Physicians}

To estimate the current annual production of primary care physicians, we used data from the American Board of Family Physicians (L. Peterson, written communication, November 2014), American Board of Internal Medicine, and American Board of Pediatrics. ${ }^{22,23}$ For internal medicine and pediatrics, we adjusted resident counts by backing out the number of fellows in each specialty. For all 3 specialties, we added counts of osteopathic residency graduates. ${ }^{24}$ Finally, using recent studies of hospitalists, ${ }^{13,25}$ we adjusted these counts by excluding estimates of the percentage of residents from each specialty likely to work as hospitalists. We also adjusted our retirement figures to exclude hospitalists, taking into account the younger composition of the current hospitalist workforce.

\section{Calculating Shortages and Additional Residency Slots, By Specialty}

From 2015 to 2035, we calculated the production of accumulated primary care physicians, assuming 2015 levels, by subtracting the number of physicians retiring from the number of physicians produced. For each year, we determined the shortage by subtracting the accumulated production from the accumulated primary care need (both overall and for population growth only). We estimated the annual additional residents needed by subtracting the annual net production from the annual additional demand caused by increased need and retirement.

We determined the specialty allocation of the additional residency slots needed using 3 scenarios: (1) additional slots are proportional to the current composition (the ratio of general internists to family physicians equals that in the AMA Masterfile), (2) additional slots are proportional to production in 2015 (the ratio of general internists to family physicians equals current production), and (3) production of general internists decreases (30\% of the combined family physician and general internist share is allocated to general internal medicine)

\section{Impact on Shortage Projections of Retirement Age and Changes in the Ratio of Population to Primary Care Physicians}

We assumed a retirement age of 66 years to be consistent with methodology from the AAMC, which found that one-half of all physicians retire by this age. ${ }^{7}$ Using the AMA Masterfile, we altered projections assuming retirement ages of 64 and 68 years. For retirement figures, we combined family medicine and general practice.

In calculating the primary care physicians needed, we assumed each primary care physician can see a certain number of visits annually and used this figure to calculate a ratio of population to primary care physicians (our proxy for panel size). Given new models of care, we also calculated shortages assuming this ratio increased and decreased by $10 \%$.

\section{RESULTS}

\section{Baseline Estimates of the Physician Primary Care Workforce and Production}

Our baseline figures for 2015, interpolating from 2010 to 2014 trends, include an estimated 89,054 family physicians, 6,668 general practitioners, 80,810 general internists, and 52,016 pediatricians in direct patient care (Table 1). For the purposes of baseline and retirement figures, medicine-pediatric physicians are embedded within the pediatrician counts. We also estimate the following baseline production rates after excluding hospitalists: 1,869 general pediatricians, 2,412 general internists, and 3,768 family physicians.

\section{Retirement of Primary Care Physicians}

In 2015, we estimate that 2,504 family physicians and general practitioners, 2,346 general internists, and 1,177 pediatricians are expected to retire. During the next decade, these numbers will increase substantially (Figure 1), reflecting the recognition of family practice

Table 1. Estimated Number of Primary Care Physicians, 2010-2015

\begin{tabular}{|c|c|c|c|c|c|c|c|}
\hline Specialty & 2010 & 2011 & 2012 & 2013 & 2014 & $\begin{array}{c}\text { Estimated } \\
2015\end{array}$ & $\begin{array}{c}\text { 2010-2014 } \\
\text { Annual Change }\end{array}$ \\
\hline Family medicine & 80,324 & 81,458 & 82,906 & 84,449 & 87,302 & 89,054 & 1,382 \\
\hline General practice & 9,557 & 8,948 & 8,058 & 7,542 & 7,247 & 6,668 & -694 \\
\hline General internal medicine & 73,598 & 73,846 & 75,195 & 76,543 & 79,340 & 80,810 & 1,018 \\
\hline Pediatrics & 47,768 & 48,042 & 48,824 & 49,719 & 51,148 & 52,016 & 439 \\
\hline Total & 211,247 & 212,293 & 214,983 & 218,253 & 225,036 & 228,547 & \\
\hline
\end{tabular}


Figure 1. Annual projected number of retiring physicians, by specialty type (2011-2035).

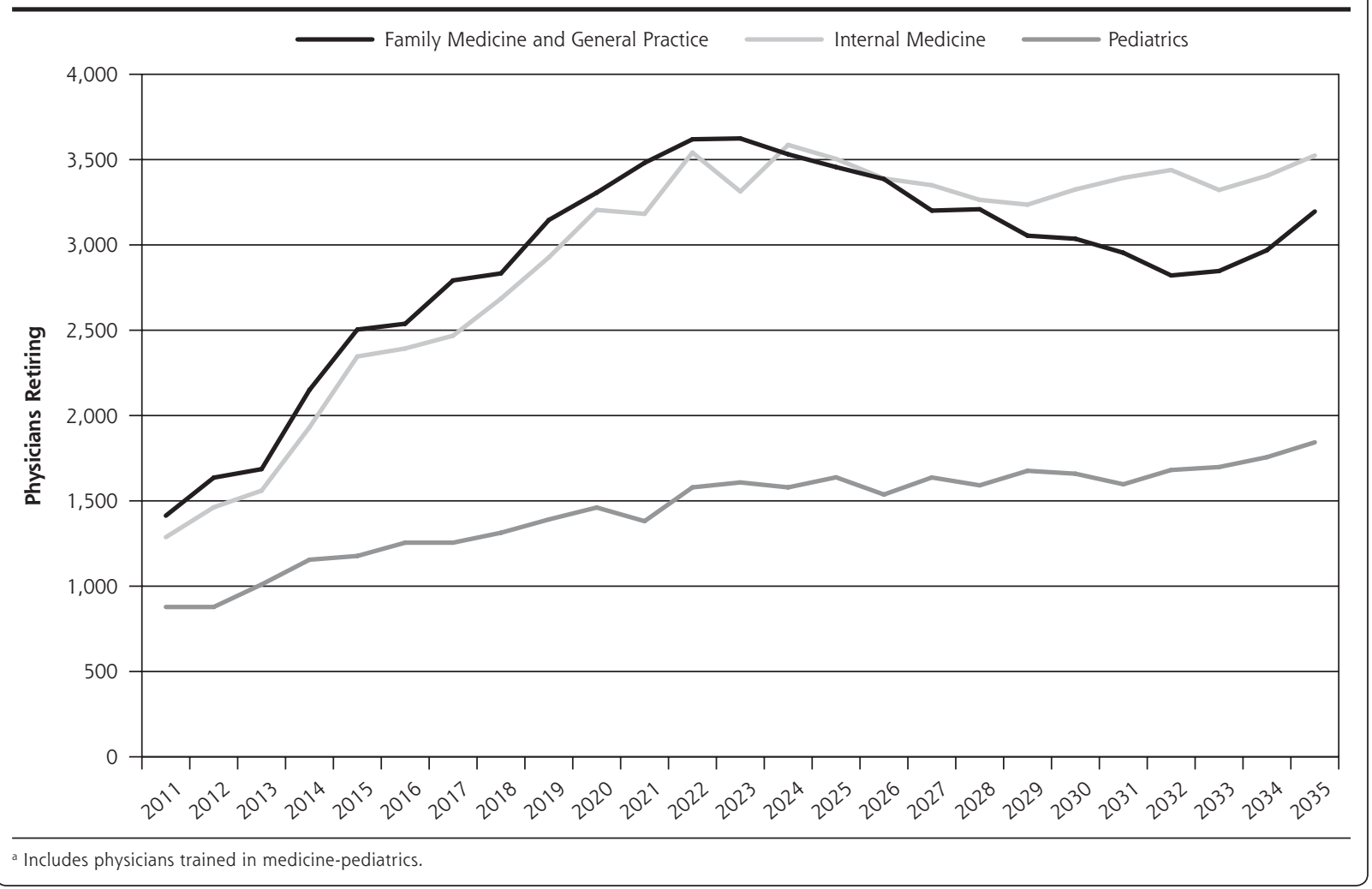

Table 2. Projected Primary Care Workforce Shortages

\begin{tabular}{ccccccc}
\hline & \multicolumn{2}{c}{ Need } & \multicolumn{2}{c}{ Supply } \\
\cline { 2 - 5 } Year & $\begin{array}{c}\text { Overall: Population Growth, } \\
\text { Aging, and Insurance }\end{array}$ & $\begin{array}{c}\text { Population Growth } \\
\text { Only }\end{array}$ & $\begin{array}{c}\text { Cumulative } \\
\text { Production }\end{array}$ & $\begin{array}{c}\text { Cumulative } \\
\text { Retirement }\end{array}$ & Shortage & Sesidents per Year \\
\hline 2015 & 228,547 & 228,547 & 8,049 & 5,819 & $-2,230$ & \\
2020 & 241,291 & 237,460 & 48,294 & 39,519 & 3,968 & 2,196 \\
2025 & 253,630 & 246,358 & 88,539 & 80,669 & 17,213 & 2,710 \\
2030 & 264,015 & 254,938 & 128,784 & 119,756 & 26,440 & 1,773 \\
2035 & 272,887 & 262,897 & 169,029 & 157,971 & 33,283 & 1,700 \\
\hline
\end{tabular}

as a specialty in 1969 and the concurrent expansion of medical schools in the 1970s. ${ }^{26,27}$

\section{Projected Shortages}

We project that demographic changes and insurance expansion will require an additional 44,340 (228,547 to 272,887 ) primary care physicians by 2035 , with population growth accounting for most of the increase (Table 2). From 2015 to 2035, at current production rates (8,049 each year), allopathic and osteopathic graduate medical education will produce 169,029 new primary care physicians. Because of retiring primary care physicians, however, this production cannot match need, resulting in a shortage of 33,283 primary care physicians by 2035 . The annual number of residents needed to address anticipated shortages varies by year, reaching a peak of 2,710 in 2025 , but then declining to 1,700 by 2035 .

\section{Composition of Additional Physicians}

Assuming the ratio of general internal medicine to family medicine is proportional to the 2015 workforce (and that the overall share of pediatricians is invariant), it will be necessary to produce by 2035 an additional 1,486 general internal medicine physicians and only 110 family medicine physicians annually (Table 3). A more realistic scenario is that the composition is proportional to current production, yielding a ratio of general internal medicine to family medicine requiring an increase in the annual production of family physicians by 973 and 
Table 3. Scenarios Projecting the Composition of Additional Residency Slots Needed in 2035

\begin{tabular}{|c|c|c|c|c|}
\hline \multirow[b]{2}{*}{$\begin{array}{l}\text { Primary Care } \\
\text { Specialty }\end{array}$} & \multirow[b]{2}{*}{$\begin{array}{c}2015 \text { New } \\
\text { Primary Care } \\
\text { Physicians }\end{array}$} & \multicolumn{3}{|c|}{ GIM to FM Ratio } \\
\hline & & $\begin{array}{l}\text { Proportional } \\
\text { to } 2015 \\
\text { Workforce }\end{array}$ & $\begin{array}{l}\text { Proportional } \\
\text { to } 2015 \\
\text { Production }\end{array}$ & $\begin{array}{c}\text { Decreases From } \\
\text { Diminished GIM } \\
\text { Production }^{\mathrm{a}}\end{array}$ \\
\hline Family medicine & 3,768 & 110 & 973 & 1,117 \\
\hline $\begin{array}{l}\text { General internal } \\
\text { medicine }\end{array}$ & 2,412 & 1,486 & 623 & 479 \\
\hline Pediatrics & 1,869 & 104 & 104 & 104 \\
\hline Total & 8,049 & 1,700 & 1,700 & 1,700 \\
\hline GIM/FM ratio & 0.64 & 13.47 & 0.64 & 0.43 \\
\hline Change in FM, \% & & 2.9 & 25.8 & 29.7 \\
\hline
\end{tabular}

More than 44,000 additional primary care physicians will be needed by 2035 to meet the demands of a growing, aging, and increasingly insured population, assuming maintenance of current ratio of primary care physicians to population and current physician retirement rates. Unfortunately, at current rates of physician production, we project a shortage of more than 33,000 primary care physicians during this 20-year period. This deficit can be eliminated by adding nearly 2,200 firstyear residency positions by 2020 , a $27 \%$ increase.

of general internists by 623 . If the recent downward trend in the number of general internists produced annually continues, reaching a hypothetical rate of 30 general internal medicine residents for every 70 family medicine residents, the number of additional family medicine residents would have to increase to 1,117 , a nearly $30 \%$ increase over current levels.

\section{Impact of Changes in Retirement Age and Population per Primary Care Physician on Shortage Projections}

If primary care physicians retire at age 64 years, the shortage increases to 38,622 , whereas delaying retirement until age 68 years contracts the shortage to 26,835 (Table 4). More dramatic fluctuations are created with changes in the ratio of population to primary care physician, an approximation of panel sizes.

\section{DISCUSSION}

As have prior shortage projections, we also used NAMCS data, population growth, and aging to explain increases in demand. Despite these similarities, our analysis is distinct in several respects. First, our projections are more current, extending to 2035. Second, we used demographic projections from the 2010 US Census (rather than the 2000 Census), which forecast substantially lower population growth. Third, although other analyses provided aggregate projections of the primary care shortage, we project the additional residency slots needed by specialty to provide specific guidance to policy makers. Finally, we project shortages in response to changes in panel size and retirement age.
The magnitude of the proposed increase is daunting, but it will also be necessary to maintain current physician-to-population ratios. Unfortunately, simply adding slots to the current hospital-based graduate medical education system is unlikely to eliminate primary care shortages. ${ }^{28}$ Evidence suggests that expanded community-based graduate medical education training, such as teaching health centers and rural training tracks, can increase the number of graduates who stay in primary care and who are trained within new models of care. ${ }^{29,30}$ Fortunately, there appears to be a growing consensus that accountability for the public investment in graduate medical education is needed. ${ }^{31}$

These projected shortages come amidst calls to expand or transform residency training. In 2013, the Council on Graduate Medical Education recommended increasing residency slots by 3,000, particularly in such high-need specialties as family medicine and general internal medicine. ${ }^{32}$ The Institute of Medicine also recommended changes to graduate medical education payment to better support the primary care workforce. ${ }^{33}$ Graduate medical education reform,
Table 4. Impact of Retirement Age and Population per Primary Care Physician Changes on Shortage Projections for 2035

\begin{tabular}{lcc}
\hline Variable & $\begin{array}{c}\text { Additional Residents } \\
\text { Needed } \\
\text { No. (\% Change) }\end{array}$ & $\begin{array}{c}\text { Projected Physician } \\
\text { Shortage by 2035 } \\
\text { No. (\% Change) }\end{array}$ \\
\hline $\begin{array}{l}\text { Baseline } \\
\text { Retirement age } \\
64 \text { y } \\
68 \text { y }\end{array}$ & 1,700 & 33,283 \\
$\begin{array}{l}\text { Population per physician } \\
10 \% \text { decrease }\end{array}$ & $2,427(43)$ & $38,622(16)$ \\
$10 \%$ increase & $1,057(-38)$ & $26,835(-19)$ \\
& $3,064(80)$ & $60,561(82)$ \\
$6,004(-82)$
\end{tabular}


paired with implementation of population-based payment experiments under the ACA that incentivize new roles for primary care physicians within broader teams, could fundamentally alter these and any other current workforce projections. ${ }^{34}$ Even so, whether payment reform would shrink or grow the panel sizes of primary care physicians remains a subject of debate, ${ }^{35}$ and the prospects for graduate medical education reform radically altering primary care outputs, particularly without substantial payment reform to narrow the gap between primary and specialty care, are unknown. More research is needed to determine whether and how new payment models, such as accountable care organizations, will affect primary care recruitment and retention.

Although new models of care have the potential to enhance recruitment and retention, they will certainly affect panel sizes, which currently range from 900 to $2,300 .{ }^{14,16}$ Assuming a ratio of population to primary care physicians of 1,406 to 1 in 2015, a $10 \%$ decrease results in shifting 141 patients per physician. Our calculations indicate that if this shift occurs nationwide, shortages will increase dramatically.

\section{Limitations}

These projections have several limitations. First, the assumptions underlying our demand calculations could change. Our model depends on accurate US Census projections. For instance, reduced population growth from 2000 to 2010 decreased projected demand. We also assumed that utilization is constant, but such factors as changes in population health, technology, ${ }^{36,37}$ patient expectations, and primary care models ${ }^{14,38}$ could change demand.

Second, the assumptions underlying our supply projections could change. For instance, hours worked per primary care physician have steadily decreased, and further erosion could limit the number of visits each primary care physician sees. ${ }^{8,10,39}$ The growing percentage of family physicians who are women may affect productivity, because women have been shown to work fewer hours. ${ }^{40-42}$ Market shifts across primary care may also occur. Pediatricians could see more adolescents while internal medicine and family medicine hospitalists could increase. Internal medicine residents may become more interested in primary care. Though the American College of Physicians is promoting general internal medicine, the impact of its efforts is undetermined.$^{43}$ Increasing internal medicine residents in primary care would reduce the deficit at no additional cost.

Obstetrics and gynecology was not included because $37 \%$ expressed minimal or no interest in primary care. ${ }^{44,45}$ We also did not include nonphysician clinicians. Auerbach et al and the Health Resources and Services Administration used theoretical modeling to suggest that a surplus of physician assistants and nurse practitioners could alleviate a portion of the primary care physician shortage. ${ }^{8,46}$ In particular, Auerbach and colleagues hypothesized that primary care teams which incorporated nonphysicians could accommodate larger panel sizes. Countering that notion, other studies of effective primary care teams working in accountable care models suggest that the opposite may also be true, namely, that smaller panel sizes may be needed to capitalize on the capacity of primary care to reduce costs and improve health. ${ }^{35} \mathrm{We}$ incorporated the potential impact of larger panel sizes, which account for Auerbach et al's nurse practitionerphysician assistant effect by proxy, into our estimates and avoided making theoretical guesses as to the exact impact made by these clinicians' contributions to the primary care workforce. Although the literature suggests that physicians, physician assistants, and nurse practitioners will all contribute to solving our shortage, it also suggests that they fulfill different roles in delivering primary care ${ }^{47,48}$; furthermore, similar to physicians, physician assistants and nurse practitioners face strong challenges to their entry into primary care, with $52 \%$ of nurse practitioners and $43 \%$ of physician assistants working in primary care and a growing percentage working in hospitals. ${ }^{49-51}$ Finally, our analysis fails to account for physician maldistribution. Many have argued that increasing the absolute number of primary care physicians without addressing distribution will only exacerbate existing access issues. ${ }^{52,53}$

To read or post commentaries in response to this article, see it online at http://www.annfammed.org/content/13/2/107.

Key words: health policy; health services research; graduate medical education; internship and residency

Submitted July 24, 2014; submitted, revised, November 12, 2014; accepted December 11, 2014.

Previous presentations: This abstract was presented at the 2014 North American Primary Care Research Group Meeting, New York, NY, November 2014.

Disclaimer: The information and opinions contained in research from the Robert Graham Center do not necessarily reflect the views or policy of the American Academy of Family Physicians.

Acknowledgments: We would like to acknowledge Claire Gibbons for assistance in editing the manuscript.

\section{References}

1. Brownlee S. Overtreated. New York, NY: Bloomsbury; 2007.

2. Berwick DM, Hackbarth AD. Eliminating waste in US health care. JAMA. 2012;307(14):1513-1516. 
3. Johnson PJ, Ghildayal N, Ward AC, Westgard BC, Boland LL, Hokanson JS. Disparities in potentially avoidable emergency department (ED) care: ED visits for ambulatory care sensitive conditions. Med Care. 2012;50(12):1020-1028.

4. Vats S, Ash AS, Ellis RP. Bending the cost curve? Results from a comprehensive primary care payment pilot. Med Care. 2013;51(11): 964-969.

5. Phillips RL, Pugno PA, Saultz JW, et al. Health is primary: family medicine for America's health. Ann Fam Med. 2014;12(Suppl_1):S1S12. http://annfammed.org/content/12/Suppl_1.

6. Colwill JM, Cultice JM, Kruse RL. Will generalist physician supply meet demands of an increasing and aging population? Health Aff (Millwood). 2008;27(3):w232-w241.

7. Dill MJ, Salsberg ES. The Complexities of Physician Supply and Demand: Projections Through 2025. Washington, DC: Association of American Medical Colleges; 2008.

8. Health Resources and Services Administration Bureau of Health. Professions, \& National Center for Health Workforce Analysis. Projecting the Supply and Demand for Primary Care Practitioners Through 2020. 2013. http://bhpr.hrsa.gov/healthworkforce/supplydemand/usworkforce/primarycare/projectingprimarycare.pdf. Accessed May 10, 2014.

9. Petterson SM, Liaw WR, Phillips RL Jr, Rabin DL, Meyers DS, Bazemore AW. Projecting US primary care physician workforce needs: 2010-2025. Ann Fam Med. 2012;10(6):503-509.

10. Health Resources and Services Administration Bureau of Health Professions. Physician Supply and Demand: Projections to 2020. 2006. http://bhpr.hrsa.gov/healthworkforce/supplydemand/medicine/physician2020projections.pdf. Accessed May 10, 2014.

11. Jolly P, Erikson C, Garrison GUS. US graduate medical education and physician specialty choice. Acad Med. 2013;88(4):468-474.

12. Chen C, Petterson S, Phillips RL, Mullan F, Bazemore A, O'Donnell SD. Toward graduate medical education (GME) accountability: measuring the outcomes of GME institutions. Acad Med. 2013;88(9): 1267-1280.

13. Kuo YF, Sharma G, Freeman JL, Goodwin JS. Growth in the care of older patients by hospitalists in the United States. N Engl J Med. 2009;360(11):1102-1112.

14. Reid RJ, Fishman PA, Yu O, et al. Patient-centered medical home demonstration: a prospective, quasi-experimental, before and after evaluation. Am J Manag Care. 2009;15(9):e71-e87.

15. Altschuler J, Margolius D, Bodenheimer T, Grumbach K. Estimating a reasonable patient panel size for primary care physicians with team-based task delegation. Ann Fam Med. 2012;10(5):396-400.

16. Alexander GC, Kurlander J, Wynia MK. Physicians in retainer ("concierge") practice. A national survey of physician, patient, and practice characteristics. J Gen Intern Med. 2005;20(12):1079-1083.

17. Wu WN, Bliss G, Bliss EB, Green LA. Practice profile. A direct primary care medical home: the Qliance experience. Health Aff (Millwood). 2010;29(5):959-962.

18. Willard-Grace R, Hessler D, Rogers E, Dubé K, Bodenheimer T, Grumbach K. Team structure and culture are associated with lower burnout in primary care. J Am Board Fam Med. 2014;27(2):229-238.

19. Bureau of the Census. Table 2: Projections of the population by selected age groups and sex for the United States: 2010 to 2050 (NP2008-T2). In: Population Division, US Census Bureau. Washington, DC: Population Division, US Census Bureau; 2008.

20. Hofer AN, Abraham JM, Moscovice I. Expansion of coverage under the Patient Protection and Affordable Care Act and primary care utilization. Milbank Q. 2011;89(1):69-89.

21. Huang ES, Finegold K. Seven million Americans live in areas where demand for primary care may exceed supply by more than 10 percent. Health Aff (Millwood). 2013;32(3):614-621.
22. American Board of Internal Medicine. Resident \& fellow workforce data. 2013. http://www.abim.org/about/examInfo/data-workforce. aspx. Accessed Nov 5, 2014.

23. American Board of Pediatrics. Workforce data 2013-2014. https:// www.abp.org/abpwebsite/stats/wrkfrc/workforcebook. pdf. Accessed Jun 20, 2014.

24. DeRosier A, Lischka TA, Martinez B. Appendix 1: Osteopathic graduate medical education 2014. J Am Osteopath Assoc. 2014;114(4): 299-303.

25. Pete Welch W, Stearns SC, Cuellar AE, Bindman AB. Use of hospitalists by Medicare beneficiaries: a national picture. Medicare Medicaid Res Rev. 2014;4(2):E1-E8.

26. Pisacano NJ. History of the specialty. https://www.theabfm.org/ about/history.aspx. Accessed Oct 17, 2014.

27. Macy J Jr. Foundation. Revisiting the medical school educational mission at a time of expansion. 2008. http://macyfoundation.org/ docs/macy_pubs/Macy_MedSchoolMission_proceedings_06-09.pdf. Accessed Oct 17, 2014.

28. Petterson S, Burke M, Phillips R, Teevan B. Accounting for graduate medical education production of primary care physicians and general surgeons: timing of measurement matters. Acad Med. 2011;86(5):605-608.

29. Chen C, Chen F, Mullan F. Teaching health centers: a new paradigm in graduate medical education. Acad Med. 2012;87(12):1752-1756.

30. Patterson DG, Longenecker R, Schmitz D, Phillips RL Jr, Skillman SM, Doescher MP. Rural residency training for family medicine physicians: graduate early-career outcomes, 2008-2012. 2013. http://depts. washington.edu/uwrhrc/uploads/RTT_Grad_Outcomes_PB_2013. pdf. Accessed Jul 11, 2014.

31. Reddy AT, Lazreg SA, Phillips RL Jr, Bazemore AW, Lucan SC. Toward defining and measuring social accountability in graduate medical education: a stakeholder study. J Grad Med Educ. 2013;5(3):439-445.

32. Council on Graduate Medical Education. Twenty-First Report: Improving Value in Graduate Medical Education. Washington, DC: Health Resources and Services Administration; 2013.

33. Institute of Medicine. Graduate Medication Education That Meets the Nation's Health Needs. Washington, DC: National Academies Press; 2014.

34. H.R. 3590. Patient Protection and Affordable Care Act. 2010. https://www.govtrack.us/congress/bills/111/hr3590/text. Accessed Nov 5, 2014.

35. Phillips RL Jr, Bronnikov S, Petterson S, et al. Case study of a primary care-based accountable care system approach to medical home transformation. J Ambul Care Manage. 2011;34(1):67-77.

36. Blanchfield BB, Heffernan JL, Osgood B, Sheehan RR, Meyer GS. Saving billions of dollars-and physicians' time-by streamlining billing practices. Health Aff (Millwood). 2010;29(6):1248-1254.

37. Shipman SA, Sinsky CA. Expanding primary care capacity by reducing waste and improving the efficiency of care. Health Aff (Millwood). 2013;32(11):1990-1997.

38. Sinsky CA, Willard-Grace R, Schutzbank AM, Sinsky TA, Margolius $D$, Bodenheimer $T$. In search of joy in practice: a report of 23 high-functioning primary care practices. Ann Fam Med. 2013;11(3): 272-278.

39. Watson DE, Slade S, Buske L, Tepper J. Intergenerational differences in workloads among primary care physicians: a ten-year, populationbased study. Health Aff (Millwood). 2006;25(6):1620-1628.

40. Association of American Medical Colleges. 2012 Physician Specialty Data Book. Washington, DC: Association of American Medical Colleges; 2012.

41. Association of American Medical Colleges. 2008 Physician Specialty Data Book. Washington, DC: Association of American Medical Colleges; 2008. 
42. Hedden L, Barer ML, Cardiff K, McGrail KM, Law MR, Bourgeault IL. The implications of the feminization of the primary care physician workforce on service supply: a systematic review. Hum Resour Health. 2014;12:32.

43. American College of Physicians. How Is a Shortage of Primary Care Physicians Affecting the Quality and cost of Medical Care? 2008. http:// www.acponline.org/advocacy/current_policy_papers/assets/primary_shortage.pdf. Accessed May 10, 2014.

44. Scroggs JA, Griffin LP, Bayerl M, Schulkin J. Obstetriciangynecologists as primary care physicians: the perspectives of health maintenance organization medical directors and obstetriciangynecologists. Obstet Gynecol. 1997;90(2):291-295.

45. Lentz GM, Ayala L, Eckert LO. A comprehensive women's health care center: are gynecologists offering primary care? Am J Obstet Gynecol. 2006;194(6):1660-1666; discussion 1666-1667.

46. Auerbach DI, Chen PG, Friedberg MW, et al. Nurse-managed health centers and patient-centered medical homes could mitigate expected primary care physician shortage. Health Aff (Millwood). 2013;32(11):1933-1941.

47. Doescher MP, Andrilla CHA, Skillman SM, Morgan P, Kaplan L. The contribution of physicians, physician assistants, and nurse practitioners toward rural primary care: findings from a 13-state survey. Med Care. 2014;52(6):549-556.
48. Hooker RS, McCaig LF. Use of physician assistants and nurse practitioners in primary care, 1995-1999. Health Aff (Millwood). 2001; 20(4):231-238.

49. Petterson SM, Phillips RL Jr, Bazemore AW, Teevan Burke B, Koinis GT. Relying on NPs and PAs does not avoid the need for policy solutions for primary care. Am Fam Physician. 2013;88(4):230.

50. Goolsby MJ. 2004 AANP National Nurse Practitioner Sample Survey, part I: an overview. J Am Acad Nurse Pract. 2005;17(9):337-341.

51. Goolsby MJ. 2009-2010 AANP national nurse practitioner sample survey: an overview. J Am Acad Nurse Pract. 2011;23(5):266-268.

52. Green LA, Dodoo MS, Ruddy G, et al. The physician workforce of the United States: A family medicine perspective. 2004. http://www. graham-center.org/online/etc/medialib/graham/documents/publications/mongraphs-books/2004/rgcmo-physician-workforce.Par.0001. File.tmp/rgcmo-physician-workforce.pdf. Accessed May 14, 2014.

53. Council on Graduate Medical Education. Physician Distribution and Health Care Challenges in Rural and Inner-City Areas. Washington, DC US Department of Health and Human Services, Health Resources and Services Administration; 1998.

\section{CHANGE-OF-ADDRESS FORM

Please complete this form and mail to the following address or fax to Annals Circulation at 913-906-6080:

Annals of Family Medicine, Circulation Department, 11400 Tomahawk Creek Pkwy, Leawood, KS 66211-2680

Check if member of sponsoring organization:

$$
\begin{array}{ll}
\square \text { AAFP } & \square \text { ABFM } \square \text { STFM } \square \text { ADFM } \\
\square \text { AFMRD } & \square \text { NAPCRG } \square \text { CFPC }
\end{array}
$$

ID number from label on your journal cover

OLD Information (Please print.)

\begin{tabular}{ll}
\hline Name \\
\hline Company (if applicable) \\
\hline Address (Street plus Apt or Ste) \\
\hline City & Postal Code (9-digit ZIP for US) \\
\hline Country & Fax \\
\hline Telephone & \\
\hline E-Mail &
\end{tabular}

NEW Information (Please print.)

\begin{tabular}{lc}
\hline Name \\
\hline Company (if applicable) \\
\hline Address (Street plus Apt or Ste) \\
\hline City & \\
\hline Country & Postal Code (9-digit ZIP for US) \\
\hline Telephone & Fax \\
\hline E-Mail &
\end{tabular}

